\title{
Observing how 'system unto system runs': WATSAN, Dignity, Health, Education and Opportunity
}

\author{
S. Mecca ${ }^{1}$, H. Davis ${ }^{2} \&$ A. Davis ${ }^{3}$ \\ ${ }^{1}$ Department of Engineering-Physics-Systems, Providence College, USA \\ ${ }^{2}$ Interactive Telecommunications Program, New York University, USA \\ ${ }^{3}$ Albert Nerken School of Engineering, The Cooper Union, USA
}

\begin{abstract}
This paper is occasioned by the WIT inauguration of a new conference on Water and Society. It reviews some of the connections between water and sanitation (WATSAN) and human dignity, security, morbidity and mortality, education and community development. It draws on the authors' experiences in Ghana and published findings related to Millennium Development Goal (MDG) studies and relevant policy analysis efforts. The application of sustainable design and problem solving to help advance the MDGs through the design and introduction of an innovative toilet system is discussed.
\end{abstract}

Keywords: WATSAN, WASH, water, sanitation, millennium development goals, new toilet, microflush-biofil toilet, hygiene, rural development, women's education.

\section{Introduction}

The occasion of this inaugural conference prompts the opportunity to focus on the themes and significance embedded in the conference title, Water \& Society. Water and sanitation (WATSAN) and WAter Sanitation and Hygiene (WASH), the conditions for which range widely for peoples throughout the world, are tightly connected and embedded in the important, though somewhat overlooked, components of the United Nations Millennium Development Goals (MDGs) \#4 (reducing child mortality) and \#7 (reducing the number of people without access to improved water and sanitation). With over $70 \%$ of our planet's surface 
covered by water, one would think that there shouldn't be a problem with water supply; yet only $2.5 \%$ of all terrestrial water is fresh water and of that, the amount that is replenished by precipitation and potentially accessible for human use at an affordable cost is less than $1 \%$ or about $0.007 \%$ of all water on earth. While this fraction of the earth's water, small as it is, would nevertheless appear to be sufficient for the population as a whole, the problem is that the quality of supply is being aggravated by pollution and the level of demand is being enhanced by an increasing world population; spatial separations of supply and demand and temporal changes in both are creating threatening situations in many regions of the world and these situations impact so many societal issues many of which will be highlighted in this conference.

It is worth noting some of the World Health Organization's (WHO's) remarks on the MDGs related to water and sanitation. On the bright side, the WHO reports [1] that "the world is still on track for reaching the MDG drinking water target (reducing by half the proportion of people without sustainable access to safe drinking water)". However, the organization reports, "but the trend appears to be deteriorating"; and regarding the sanitation goals, "on current trends, the world will miss the sanitation target by more than half a billion people." "Some 2.5 billion people worldwide are without improved sanitation." The sanitation conditions in sub-Saharan Africa are particularly poor with $50 \%$ of all people on the 'open defecation' or 'unimproved' rungs of the so-called sanitation ladder.

\section{WATSAN, morbidity and mortality}

If society has been a recipe book for the wellbeing of humanity, then water and sanitation have been its crucial ingredients. Access to water has influenced the growth and demise of civilizations and is clearly critical to the survival of individuals and their societies. One of the most profound lessons that those involved in water and sanitation soon learn is the connection of WATSAN conditions to so many of the other basic individual and societal challenges facing peoples of the world. To highlight a few of the fundamental connections, water is clearly linked to survival; water is linked to sanitation; sanitation and water are linked to health, water and sanitation are linked to education, especially to the education of women. Some of these linkages are shown in Figure 1. Studies connecting WATSAN conditions and morbidity and mortality have been extensively reported. See the recent ref [2] and references cited therein. Exposure to pathogenic bacteria and disease-causing parasites is increased both directly and indirectly with sanitation systems that do not isolate waste from human contact, e.g. open defecation, bucket and hanging latrines, open pit latrines and the like. Lack of hand-washing with soap and water likewise increase exposure to fecal coli and other pathogenic bacteria.

Consider the 550 million children under 5 years of age in the world; diarrheal disease related deaths alone take approximately 1.7 million per year; this is larger than the mortality associated with malaria and HIV combined. The prevalence of diarrhea can be reduced by 20 to $40 \%$ if households had improved access to water and sanitation. While the absolute mortality rates for children 


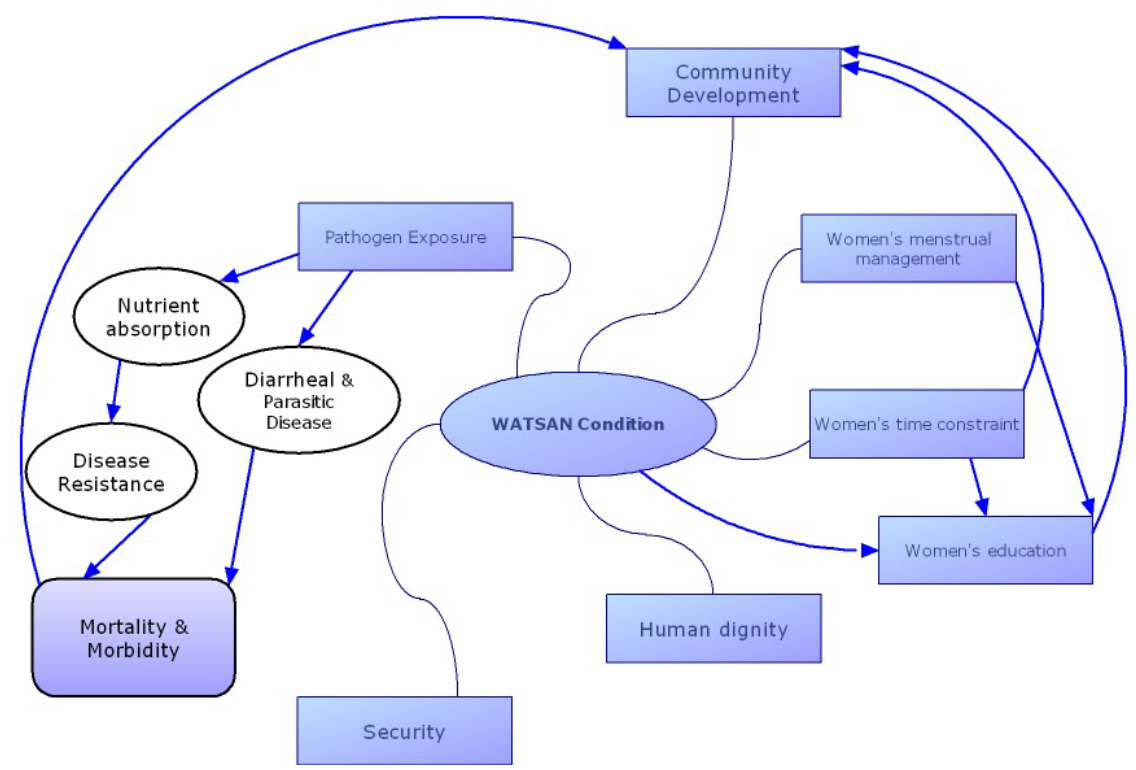

Figure 1. The condition of water and sanitation and the linkage with other issues in society.

under 5 in developing countries as a whole have been dropping, in some regions the rates are increasing. In Sub-Saharan Africa (SSH) under five deaths have increased "from 4.3 million in 1990 to 4.6 million in 2007 " according to a recent MDG update [3], a result only partly explained by increasing fertility rates in $\mathrm{SSH}$.

WATSAN conditions also impact a person's ability to absorb nutrients and this can impact resistance to other disease. Finally, while the definitive experimental validation is yet to be published and the experimental trials as of this writing are still in the early stages of formulation, there is a not unreasonable hypothesis that a major cause of undernutrition in children is a condition known as tropical or environmental enteropathy (EE), which might possibly be mitigated by improved sanitation, and that EE rather than diarrhea might prove to be the cause-effect pathway to child stunting [4]. According to Humfrey [4], $32 \%$ of the 550 million under 5 children in the developing world are stunted and this condition is responsible for $20 \%$ of under-five mortality; it results in fewer days and years in school, low performance in school, cognitive deficiencies, and unrealized economic opportunity. Stunted girls have an increased risk of having stunted children [4]. If the aforementioned hypothesis proves to be correct, the impact of the WATSAN condition on child mortality and morbidity will be even more serious than we now think and this impact will have an even greater bearing on economic development in the developing world. 


\section{WATSAN and women's issues}

The authors' efforts in sanitation have been focused on Ghana in West Africa. Through the Ghana Sustainable Aid Project (GSAP) [5] we have also been working on programs to help keep young girls in school, a task that is made challenging by community attitudes relating to women's education. There might be enough resources for the boy's continuance in secondary school but frequently not for the girl in the family. Even the headmistresses at some of the village schools remark that 'the girls are not as interested in school and their attendance shows this'. When one examines the attendance register with the headmistress, you can observe a pattern. Each month you see girls absent for 3-4 consecutive days; of course they are absent when there is no way for them to manage their menstruation. According to an IRC report [6], the lack of privacy afforded by gender-specific sanitation facilities results in absenteeism some 10$20 \%$ of the time. Indeed WATSAN conditions in schools are tied to women's education but there is another linkage as well. In the village home, it generally falls on the girls to secure the daily water needed by the family. The lack of an accessible and safe water supply results in women (and the girls in the family) having to spend a disproportionate (compared to their male family counterparts) amount of time, otherwise available for school and study (or work), fetching water. Girls shoulder twice the burden of boys and in several SSA countries, over $25 \%$ of the population takes more than 30 minutes to "make one water collection round trip" [1]. All of this results in a severe strain on time, loss of productivity and a resultant negative (short and long term) impact on economic development in the community.

\section{Economic impact of sanitation condition}

The economic impacts of poor sanitation have been studied by the World Bank and WSP, the latter having completed recent desk studies of the impacts in several African nations, including Ghana [7]. The Ghana study indicates an annual loss of some 420 million GHC or 290 million USD, the equivalent of $\$ 12$ per person or $1.6 \%$ of Ghana's GDP. A list of the cost factors is given in Table 1. The calculated annual loss estimates are the starred (*) entries. Nonstarred entries are less well established estimates.

The aforementioned impacts of WATSAN on women's time and school attendance were not assessed in the WSP study. Clearly, the figure of \$290 M is an underestimate and, conservative as it is, is staggering considering that it would require less than the loss equivalent in sanitation investment to improve the sanitation condition of all of the country's 24.8 million people. We look at the investment issue in a subsequent section of this paper. WSP carried out similar desk studies for Nigeria, Kenya, Mozambique and Rwanda and reported these at the AfricaSan 3 Conference in Rwanda in July 2011. The losses, similarly calculated, are shown in Table 2. 
Table 1: $\quad$ Losses due to poor sanitation in Ghana from ref [7].

\begin{tabular}{|l|l|}
\hline \multicolumn{1}{|c|}{ Factor } & \multicolumn{1}{|c|}{ Estimated Loss in US\$ } \\
\hline Premature deaths & $215 \mathrm{M} *^{*}$ \\
\hline Healthcare expenditures & $54 \mathrm{M} \$$ \\
\hline Access time (finding a place to defecate) & $19 \mathrm{M} \$ *^{*}$ \\
\hline Tourism & $8.5 \mathrm{M} \$$ \\
\hline Funeral costs & $2.9 \mathrm{M} \$$ \\
\hline Productivity while sick or accessing healthcare & $1.5 \mathrm{M} \$$ \\
\hline Epidemic outbreak response (e.g. to cholera) & $1.2 \mathrm{M} \$$ \\
\hline $\begin{array}{l}\text { Cognitive development related impacts, water } \\
\text { impacts, excreta re-use }\end{array}$ & Not estimated in the study \\
\hline
\end{tabular}

Table 2: Comparison of costs associated with poor sanitation determined by WSP.

\begin{tabular}{|l|c|c|}
\hline Country & Loss in US\$/person & Loss in \% GDP \\
\hline Nigeria & $\$ 20$ & $1.3 \%$ \\
\hline Ghana & $\$ 12$ & $1.6 \%$ \\
\hline Kenya & $\$ 8$ & $0.9 \%$ \\
\hline Mozambique & $\$ 6$ & $1.2 \%$ \\
\hline Rwanda & $\$ 5$ & $0.9 \%$ \\
\hline
\end{tabular}

\section{The sanitation ladder, security and dignity}

The so-called sanitation ladder, which roughly displays the sanitation options available to people, is shown in Figure 2. Included is the sanitation coverage of Africa and of Ghana (in \%) for each level of the ladder.

Some 4.8 million Ghanaians (20\%) defecate in the open or 'in the bush'; 16 million (67\%) use unsanitary or shared (public) latrines often open pits; only $13 \%$ of the country's population has access to what is called 'improved' facilities. We have spoken of some of the linkages to health, the economy and education but what about to security and human dignity. In our early studies of public toilets in Ghana, we were surprised to observe the long queues that would form at a public latrine in a village beginning at 4 AM, hours before the work day begins. We wondered about why people and especially women would be relieving themselves at such an early hour until we realized that the traditional habit of open defecation for women presents a particular challenge. To preserve modesty, women without access to a latrine would relieve themselves in the bush under the cover of darkness and this habit has resulted in gender-based crimes (harassment and sexual attacks); those who have experienced such acts will live with fear and/or ignore the need to relieve themselves, resulting in increased incidence of constipation and urinary tract infections - how 'system unto system 


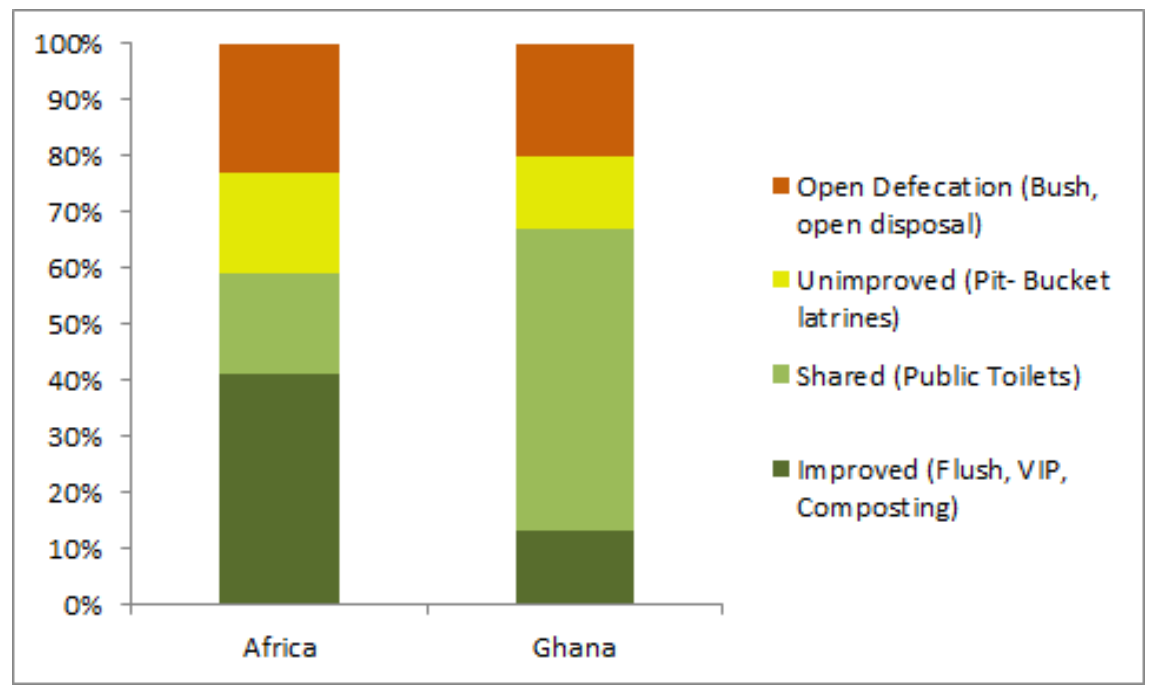

Figure 2. Sanitation ladder and coverage in Africa and in Ghana

runs'. In any event, the early use of the latrine appears to be tied to a culture of open defecation under darkness for women and men.

Anyone visiting a public latrine in Ghana (and I suspect other countries as well) can observe that patrons of the facility will remove their clothing before entering. They do this because of the filthy condition of the toilet; they are afraid of spoiling their clothes. The loss of dignity is appalling. In her poignant essay on the history of toilets in Accra [8], Deborah Pellow of Syracuse University argues, "...there is also the simple issue of environmental justice: the rights of all urban dwellers, in North or South, developed or developing countries, to the provision of convenient and functional toilet facilities."

\section{GSAP vision and action plan}

We have focused on the sanitation side of WATSAN conditions where 2.5-2.6 billion of the world's population people still lack access to improved sanitation facilities; for the water side, 884 million people around the world lack access to improved drinking water sources. In regions such as SSA, the proportions of people lacking access are much higher. We have emphasized the linkages of WATSAN condition to health, education, community development, security and basic human dignity. We briefly turn our attention now to an approach and a vision for changing WATSAN conditions, thus impacting the menace such conditions impose on society and the lives and opportunities of people.

Investments in WATSAN improvements pay off. According to the WHO, every dollar invested in water and sanitation in developing regions results in an economic benefit in the range of $\$ 5$ to $\$ 28$ [9]. Further, in the aforementioned work of Günther and Fink [2], investment in WATSAN infrastructure can reduce 
under-five child mortality by 25 deaths per 1000 births, a change that represents $40 \%$ of the difference between the present mortality rate and the target of the MDG. In some SSA countries the mortality reduction is as high as 50 deaths per 1000 births according to their calculations. While the upfront costs associated with implementing traditional technologies are high, these nevertheless represent a good investment; according to the study, countries would spend between 65 and $80 \%$ of their GDP per capita per life year saved, which is a sound infrastructure investment. This study looked at two intervention scenarios: 1. Basic improved water and sanitation and 2. Piped water and flush toilets and compared the resulting impacts on under-five child mortality to impacts from increasing the education of women in the study households using another two scenarios: 3. All mothers receive at least some primary education and 4. All mothers receive at least some secondary education. For SSA, the lives saved per 1000 live births for scenarios 1, 2, 3 and 4 are 11, 31, 6 and 31 respectively. While piped water and flush toilets and some secondary education for all mothers produce similar results, both are challenging pursuits. Yet, it is interesting that the multiple links between WATSAN condition and women's education we have highlighted suggest a cascading-reinforcing synergy that especially encourages the development of effective strategies for improving such conditions. Günther and Fink, quoting an earlier study by Hutton and Haller [10], computed present value of intervention costs over the lifetime of the systems. In SSA the present value of costs (computed with a $3 \%$ discount rate) for basic sanitation, basic water, flushed toilets and piped water are 781, 309, 2099 and 2315 \$ per household respectively. Much of the effort in sanitation is centered on campaigns to move people from open defecation to the next rungs of the sanitation ladder realizing those scenario 1 gains. At GSAP, we have been focusing on the development of an effective and acceptable technical solution coupled with a deployment plan that scales up in a sustainable way and pushes people to near the top rung of the ladder to realize scenario 2 gains in under-5 mortality.

With the support of the Bill and Melinda Gates Foundation, we are in the midst of field studies in Ghana to validate a unique toilet design that couples a biofilter-composing toilet designed by a Ghanaian engineer colleague (the Biofil Digester) with a (patent pending) Microflush valve designed by one of the authors (SM) and a student in our laboratory at Providence College. The valve flushes on a mere $150 \mathrm{cc}$ of water. The early results are very positive and will be published in an upcoming paper. The preliminary cost estimates (even for early prototype models) are such that it might be no more expensive to deploy this technology than it is to install VIP (ventilated improved pit latrine) systems. The deployment model will be through either private- or government- or partnersponsored family toilet cooperatives. A prototype one-stall installation is shown in Figure 3.

One or more households/families would share in a Microflush-Biofil coop facility, paying back the sponsoring authority a small per member sum (typically $1-1.5$ GHC or $\$ 0.70-\$ 1.00$ ) per month until the coop loan is paid (typically 3 years). Such payments are less than what would be paid in a public toilet and 

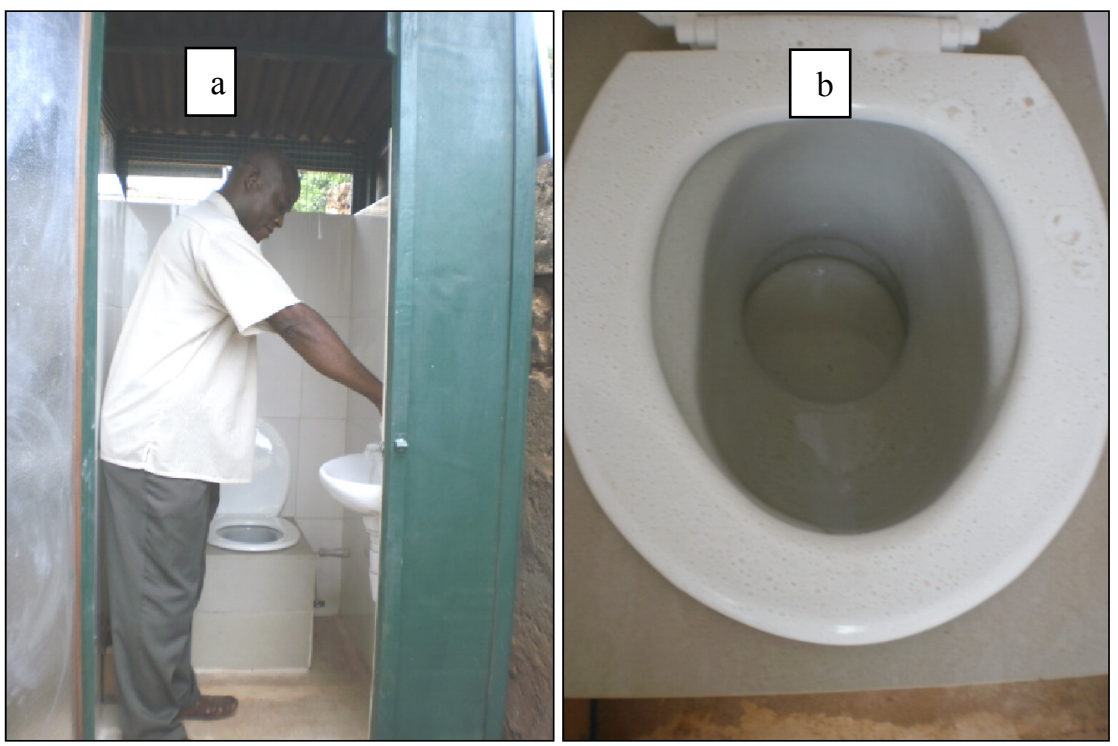

Figure 3. a. Patron using single stall prototype Microflush-Biofil toilet;

b. toilet showing the Microflush valve.

will result in family ownership of a share of the coop facility. Ownership offers the opportunity for improved maintenance and care over what one sees in a publically managed facility. A significant loan fund would kick off the operation. Coop payments would be used to fund subsequent coop toilets in a typical revolving fund operation. Our optimism is fuelled by the initial costs cited in the aforementioned studies [2] and [10]; in SSA this cost was estimated as $\$ 120$ per person. Our prototype systems cost between $\$ 30$ and $\$ 50$ per person installed. They dislodge every 2 years providing valuable compost. Each stall is outfitted with a small hand washing sink that releases - in wetting, washing and rinsing stages - the right amount of water for a subsequent toilet (micro)flush . So the toilet is flushed with grey water from the hand wash and the resulting small volume of blackwater is twice filtered before it is allowed to leach through the soil; 500 uses of a multi-stall facility produces a little more than 20 gallons of such black water (compared with 500-700 gallons from a standard flush toilet).

\section{Conclusions}

Alexander Pope in his Essays on Man [11] noted: "Observe how system unto system runs; what other planets circle other suns?" We have observed how 'system unto system runs' from WATSAN unto education, development, dignity, opportunity, security and health. We have also observed how WATSAN investments can pay off in many realms and how these payoffs can feed back to reinforce benefits as in the case of WATSAN influencing under-5 mortality and women's education and then the latter re-influencing under-5 mortality. We are 
in the first stages of proving a simple and innovative sanitation solution, the Microflush-Biofil system that, with little or no additional investment beyond what is required to move people from 'open defecation' to the next rung of the sanitation ladder, can move people in the developing world to or near the top of that ladder, an ambitious but doable goal.

\section{References}

[1] Progress on Sanitation and Drinking Water: 2010 Update, WHO/UNICEF Joint Monitoring Programme for Water Supply and Sanitation.

[2] Günther, I. \& Fink, G, Water and Sanitation to Reduce Child Mortality: The Impact and Cost of Water and Sanitation Infrastructure, Policy Research Working Paper, The World Bank Development Economics Prospects Group, March 2011.

[3] The Millennium Development Goals Report 2009. New York: United Nations.

[4] Humfrey, J., Child undernutrition, tropical enteropathy, toilets, and handwashing, The Lancet, Volume 374, Issue 9694, pp 1032-1035, 19 September 2009.

[5] The Ghana Sustainable Aid Project (GSAP), www.ghanasustainableaid.org.

[6] IRC International Water and Sanitation Centre, 'Adolescent Girls and School Hygiene, Sanitation and Water', School Sanitation and Hygiene Education Notes \& News, IRC, Delft, Netherlands, 2005. Cited in "Raising Clean Hands."

[7] Ghana loses GHC420 Million annually due to poor sanitation, Water and Sanitation Program (WSP), www.wsp.org, 2011.

[8] Pellow, D., And a toilet for everyone, Visions of the City: Accra in the $21^{\text {st }}$ Century, ed. R. Tettley \& A. Korantema, Ghana Institute of Architects, Woeli Publishing, 2002.

[9] Progress for Children Unicef 2006.

[10] Hutton G., \& Haller, L., Evaluation of Costs and Benefits of Water and Sanitation Improvements at the Global Level, World Health Organization, 2004.

[11] Pope, A. Essays on Man, 1733-34. 